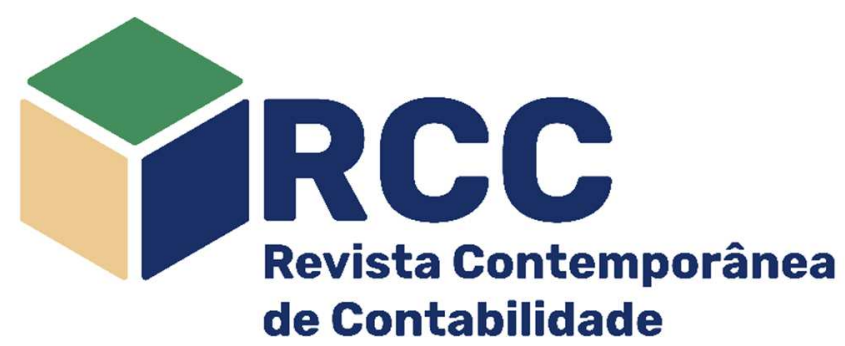

\title{
Relação entre os dividendos e a classificação de rating de empresas brasileiras
}

\author{
Relationship between dividends and rating classification of Brazilian companies

\section{Relación entre dividendos y la clasificación de rating de empresas brasileñas}

\author{
Cristiano Augusto Borges Forti* \\ Doutor em Financas EAESP (FGV) \\ Professor de Finanças na Faculdade de Gestão e \\ Negócios - FAGEN (UFU), Uberlândia/MG, Brasil \\ crforti@gmail.com \\ https://orcid.org/0000-0003-4678-7323 (1) \\ Kellen Silva Freitas \\ Mestranda em Administração no PPGGO (UFU), \\ Uberlândia/MG, Brasil \\ k sfreitas@hotmail.com \\ https://orcid.org/0000-0002-1660-5050 (1)
}

Endereço do contato principal para correspondência*
Rua Antonia Saltão de Almeida, 58, Bairro Santa Mônica, CEP $38.408-118$ - Uberlândia/MG Brasil

\begin{abstract}
Resumo
Este estudo investigou a relação entre a política de dividendos e a classificação de rating das empresas listadas na B3 de 1995 a 2017. Para isto, verificou duas hipóteses. (a) se dentre as empresas possuidoras de rating, as que têm melhor classificação distribuem mais dividendos, e (b) se dentre todas as firmas, as com classificação de rating distribuem mais ou menos dividendos do que aquelas que não a tem. $A$ amostra composta de 330 empresas, das quais 79 possuem rating, foi submetida à análise de regressão pelos modelos GMM, Matching Estimators e Tobit, considerando as variáveis: rating, dividendos divididos pelo Patrimônio Líquido, alavancagem, tamanho e crescimento dos lucros. Como resultado encontrou-se uma relação significante entre a distribuição de dividendos e a classificação de rating. Conclui-se, portanto, que tanto o rating quanto os dividendos, neste estudo, são elementos de sinalização de informações ao mercado. Palavras-chave: Dividendos; Rating; Sinalização
\end{abstract}

\begin{abstract}
This study investigated a relationship between a dividend policy and credit rating of firms listed on the B3 from 1995 to 2017. For this, it was verified two hypotheses. (a) among the firms with credit rating, those with the highest ranking pay more dividends, and (b) if among all firms, those with credit rating pay more or less dividends than those who do not. The sample of 330 companies, of which 79 with a rating, was submitted to regression analysis using GMM, Matching Estimators and Tobit Models, using as variables: rating, dividends by equity, leverage, size and earnings growth. As a result, we found a significant relationship between the payment of dividends and the credit rating. We concluded, therefore, that both the rating and the dividends, are elements of information signaling to the market.
\end{abstract}

Keywords: Dividends; Rating; Signaling

\section{Resumen}

Este estudio investigó la relación entre la política de dividendos y la clasificación de rating de las empresas listadas en la B3 de 1995 a 2017. Para ello, verificó dos hipótesis. (a) si entre las empresas poseedoras de rating, las que tienen mejor clasificación distribuyen más dividendos, y (b) si entre todas las firmas, las que tienen clasificación de rating distribuyen más o menos dividendos comparado con las que no la tienen. La muestra está compuesta por 330 empresas, de las cuales 79 tienen rating, fue sometida al análisis de regresión por los modelos GMM, Matching Estimators y Tobit, considerando las variables: rating, dividendos dividido por el patrimonio líquido, apalancamiento, tamaño y crecimiento del lucro. Como resultado se encontró una relación significante entre la distribución de dividendos y la clasificación de rating. Se concluye que tanto el rating como los dividendos, en este estudio, son elementos de señalización al mercado.

Palabras clave: Dividendos; Rating; Señalización 


\section{Introdução}

A política de dividendos é um tema controverso na literatura de finanças, principalmente no que tange a sua relevância. Sabe-se, no entanto, que ela juntamente com as políticas de investimentos e financiamento, formam os três pilares mais importantes das decisões em finanças corporativas (BLACK, 1976; FAMA; FRENCH, 2001).

$\mathrm{Na}$ literatura sobre política de dividendos há duas correntes: aquela que defende a relevância dos dividendos e seu conteúdo informacional ao mercado, cujo precursor é Lintner (1956); e aquela contrária, que defende a irrelevância dos dividendos, tendo como precursores Miller e Modigliani (1961). Pode-se ainda verificar a teoria da sinalização através dos dividendos, como proposto por Ramasastry, Kose e Williams (1987), que defendem que as empresas utilizam os dividendos para sinalizar ao mercado sobre o seu desempenho financeiro atual e futuro. Esta teoria encontra suporte empírico em diversas pesquisas (NISSIM; ZIV, 2001; LOSS; SARLO NETO, 2003; CIOFFI; FAMÁ, 2010; FORTI; SCHIOZER, 2015).

De forma complementar, há ainda a teoria de assimetria informacional, que argumenta que os dividendos podem ser utilizados para reduzir conflitos entre acionistas e credores e acionistas e gestores (SHAO et al., 2013; ASHRAF; ZHENG, 2015; CHANG et al., 2018). Os pesquisadores de assimetria informacional buscaram evidenciar o papel dos dividendos na redução de conflitos gestor-acionista e acionista-credor, descrevendo que os credores, mesmo não sendo os beneficiários diretos dos dividendos podem se utilizar da informação dos gestores para avaliar seus riscos e políticas de crédito (SHAO et al., 2013; ASHRAF; ZHENG, 2015; CHANG et al., 2018).

Dentre os temas ligados a sinalização e assimetria, pode-se destacar o trabalho de Boldin e Leggett (1995), que buscaram evidenciar a relação da política de dividendos e a qualidade dos bancos americanos medida pelo seu rating. Os coeficientes mostraram-se positivos, indicando que há uma forte relação entre dividendos e saúde financeira dos bancos. Anos depois, Khieu e Pyles (2016) pesquisaram a influência de mudanças no rating de crédito das empresas em suas políticas de dividendos e investimentos. Os autores encontraram que existe uma persistência no pagamento de dividendos mesmo quando as empresas sofrem uma redução em sua classificação de crédito, enquanto que seus investimentos declinam diante da redução do rating.

Silveira, Takamatsu e Avelino (2017) defendem que o rating de crédito expressa uma opinião, por intermédio de escalas, sobre a qualidade do crédito de empresas, sendo utilizando como medida de avaliação de risco no mercado. Desta forma supõe-se que os gestores preocupados com sua classificação de rating, para fins de financiamento, podem querer aumentar ou manter os níveis de dividendos influenciando a política de dividendos com objetivo de sustentar ou mesmo melhorar sua classificação de crédito.

Contudo, é relevante destacar que nem sempre os resultados das pesquisas globais sobre dividendos se aplicam fidedignamente ao Brasil, já que o país apresenta algumas características particulares, como a forma de tributação, a existência dos dividendos mínimos obrigatórios (DMO) e os Juros sobre Capital Próprio (JSCP). Isto torna o estudo sobre a relevância dos dividendos na redução de assimetria e sinalização ao mercado no Brasil, ainda mais interessante, visto que existem poucos estudos acadêmicos sobre o assunto.

Diante do exposto, surge o seguinte problema de pesquisa: qual a relação entre a distribuição de dividendos das empresas listadas na B3 e sua classificação de rating? De forma complementar, busca-se investigar os seguintes aspectos adjacentes: se os dividendos são influenciados pela classificação de crédito das empresas, e se a classificação de rating fornece sinalização complementar aos dividendos.

O objetivo geral deste trabalho é investigar a relação entre a distribuição de dividendos das empresas listadas na Bolsa Brasileira de 1995 a 2017 e sua classificação de rating. Para isto, pretende-se de forma específica avaliar se dentre as firmas com classificação de rating, aquelas com melhor classificação distribuem mais dividendos, e também se dentre todas as empresas, a distribuição de dividendos das que possuem rating difere daquelas que não o possuem. Desta forma será possível identificar se a classificação de crédito das empresas possui conteúdo informacional (sinalização) e se este compete ou complementa as informações fornecidas pelos dividendos aos investidores.

A fim de atender esta investigação, foram obtidos dados nas bases Thomson Reuters e Economática. A análise se concentrou na relação entre o pagamento de dividendos e a classificação de rating que a empresa possuía no momento deste pagamento. Outras características das empresas foram controladas, como tamanho, lucratividade, crescimento dos lucros e outras. A metodologia estatística utilizado foram métodos robustos de regressão múltipla com dados em painel e quasi-experimentos.

Acredita-se que este estudo contribuirá com a literatura sobre política de dividendos no Brasil, principalmente no que tange a sinalização dos dividendos e sua relação com os credores na redução de assimetrias informacionais, visto que há poucos estudos sobre o assunto no país. Além disso, espera-se que seja um incentivo para novas pesquisas. $O$ artigo está estruturado da seguinte forma: a seção 2 apresenta o referencial teórico sobre política de dividendos e agências de rating. A seção 3 , a metodologia de pesquisa adotada neste estudo. A seção 4 descreve os resultados e por fim a seção 5 apresenta as considerações finais. 


\section{Referencial Teórico}

\subsection{Dividendos e Juros sobre Capital Próprio}

Dividendo é a parcela do lucro apurado pela empresa que é distribuída aos acionistas (BRASIL, 1976). Representa destinações do lucro líquido do exercício, de lucros acumulados ou de reserva de lucros, para os acionistas da sociedade. Sua forma de distribuição será regulada pelo estatuto social da sociedade que deve estar de acordo com a Lei das Sociedades por Ações (SANTOS; SCHMIDT, 2011).

A Lei no 6.404/76 dispõe sobre as sociedades por ações no Brasil, tendo sido alterada e acrescentada pela Lei no 10.303/01 e Lei oํ 11.638/07, respectivamente. Antes da vigência da Lei no $6.404 / 76$, a distribuição de dividendos estava sujeita ao livre arbítrio de acionistas controladores quando o estatuto social da empresa não regulava sobre esta questão. No entanto, desde que esta lei entrou em vigor, determinou que "os acionistas têm direito de receber como dividendo obrigatório, em cada exercício, a parcela dos lucros estabelecida no estatuto ou, se este for omisso, a importância determinada de acordo com as seguintes normas [...]" (BRASIL, 1976).

O dividendo mínimo obrigatório estabelecido pela Lei № 6.404/76 é um assunto controverso na literatura. Autores como Loss e Sarlo Neto (2006) defendem que se por um lado a restrição legal impede o estabelecimento de uma política ótima de dividendos por parte da administração e ainda reduz os recursos internos disponíveis para a empresa financiar novos projetos, por outro lado a imposição legal resulta em proteção aos acionistas minoritários, já que os controladores poderiam optar pela maior retenção dos recursos em seu próprio benefício. Martins e Novaes (2012) contradizem estes autores. Seu trabalho investiga se os DMO realmente reduzem os investimentos por parte das empresas. A partir da análise de empresas não financeiras listadas na B3 de 2005 a 2009, não encontraram uma relação significativa de influência entre estas variáveis, ou seja, os DMO não interferem de forma significante na política de investimentos da empresa.

Martins e Novaes (2012) identificaram ainda que apesar do intuito de proteger os acionistas minoritários, a Lei oㅡ 6.404/76 apresenta algumas lacunas que torna esta proteção fraca. A reserva legal e a reserva especial são exemplos de lacunas que fazem com que as empresas brasileiras eventualmente não paguem os dividendos. A pesquisa evidencia que $67 \%$ de sua amostra adotam a reserva legal e $26 \%$ não distribuem dividendos em algum momento.

Vancin e Procianoy (2016), investigando a influência dos DMO utilizando pagamentos de dividendos entre 2007 e 2013 de empresas brasileiras, encontraram evidências que as que pagavam os dividendos acima do nível mínimo obrigatório, o faziam por motivações diferentes das motivações de empresas que pagavam o mínimo. Este fato levanta questionamentos sobre os modelos de investigação de dividendos no Brasil que não levam em consideração os DMO em sua modelagem.

Galvão, Santos e Araújo (2018), investigando o pagamento de dividendos de empresas brasileiras, encontraram que mais de $60 \%$ das distribuições estavam acima dos DMO.

No Brasil, além do dividendo mínimo obrigatório, existe uma forma alternativa de distribuição dos resultados denominada de Juros Sobre o Capital Próprio (JSCP), que foi instituído pela Lei no 9.249/95 e posteriormente alterado pela Lei no $9.430 / 96$. Sua adoção pela empresa não é obrigatória.

Criado como um incentivo para compensar o fim da correção monetária dos balanços das firmas, o JSCP é calculado mediante a aplicação de um percentual determinado pela firma, denominado de taxa de juros de longo prazo (TJLP), sobre o seu patrimônio líquido, sendo depois contabilizado como despesa financeira (MALAQUIAS et al., 2007). Esta contabilização permite a empresa, para efeitos de apuração do lucro real, sua dedução da base de cálculo na apuração do imposto de renda (IR) e também, com a Lei no 9.430/96, sua dedução da base de cálculo na apuração da contribuição social (CSLL), o que representa benefício tributário para a firma. Vale ressaltar que esta dedução está limitada as restrições legais estabelecidas pela Lei no 9.249/95.

Segundo Futema, Basso e Kayo (2009), o JSCP pode ser interpretado como sendo uma forma alternativa de dividendos, já que uma vez pago pode ser considerado para o cumprimento do dividendo mínimo obrigatório. No entanto, cabe destacar que diferentemente dos dividendos que não sofrem tributação, o JSCP sofre retenção na fonte à alíquota de $15 \%$ para efeito de imposto de renda quando do seu pagamento a pessoa física. Pode ser compensado futuramente para as pessoas jurídicas (MARTINS; FAMÁ, 2012).

\subsection{Política de Dividendos}

A política de dividendos não é apenas uma decisão sobre o quanto pagar ao acionista. Ela é também uma decisão sobre o quanto ficará retido na firma, bem como dos motivos que levaram a esta retenção. É tomada pela administração da empresa e deve visar à maximização da riqueza dos acionistas (BLACK, 1976; LOSS; SARLO NETO, 2003; GALVÃO; SANTOS; ARAÚJO, 2019).

A literatura em finanças sobre política de dividendos é bastante ampla e apresenta em sua conjuntura várias abordagens, não havendo um consenso por parte dos pesquisadores em relação a todas elas: teoria do pássaro na mão, irrelevância dos dividendos, preferência tributária, teoria de agência, assimetria informacional e teoria da sinalização (MARTINS; FAMÁ, 2012). 


\subsubsection{Teorias e estudos sobre política de dividendos}

As teorias sobre política de dividendos dividem-se em clássicas e novas teorias, conforme Figura 1. As teorias clássicas, segundo Martins e Famá (2012), são: teoria do pássaro na mão, defendida por Lintner (1956) e Gordon (1959), e teoria da irrelevância dos dividendos, proposta por Miller e Modigliani (1961). A primeira defende que em um mundo de incertezas os acionistas preferem o recebimento dos dividendos correntes aos ganhos de capital futuro, devido ao menor risco associado nesta alternativa. Logo, os dividendos são considerados relevantes para sinalizar o crescimento dos lucros da empresa para o mercado. Contudo, a teoria da irrelevância dos dividendos, contraria esta corrente conservadora e argumenta que em um mercado perfeito (sem impostos e sem custos de transação) a política de dividendos seria indiferente, uma vez que neste caso interessa aos investidores a política de investimentos da empresa e o lucro pela entidade auferido, independentemente de sua distribuição ou não (LOSS; SARLO NETO, 2003; MARTINS; FAMÁ, 2012).

Figura 1: Teorias sobre política de dividendos

\begin{tabular}{l|l}
\hline Teorias Clássicas & - Teoria do pássaro na mão; \\
\hline \multirow{3}{*}{ Novas Teorias } & - Teoria da irrelevância dos dividendos; \\
& - Teoria da preferência tributária; \\
& - Assimetria informaciacional; \\
& - Teoria da sinalização. \\
\hline
\end{tabular}

Fonte: Elaborado pelos autores

O mercado perfeito proposto por Miller e Modigliani (1961) mostrou-se idealista e não condizente com a realidade das firmas. Novos estudos foram realizados buscando avaliar então a relevância da política de dividendos dada às imperfeições de mercado. Surgem, a partir de então, novas teorias sobre o assunto: teoria da preferência tributária, teoria de agência, assimetria informacional e teoria da sinalização.

A teoria da preferência tributária, proposta por Brennan (1970) e Litzenberger e Ramaswamy (1979), defende que os investidores preferem uma política de dividendos cuja tributação lhes seja a menor possível, ou seja, se os dividendos forem mais tributados que o ganho de capital, os investidores preferirão os ganhos de capital uma vez que só serão tributados quando da venda da ação.

A teoria da assimetria informacional, segundo Martins e Famá (2012), diz que os gestores são detentores de informações estratégicas privilegiadas em detrimento de alguns investidores (acionistas minoritários), principalmente quanto à perspectiva futura de fluxo de caixa. Diante disso, a fim de se evitar conflitos, os gestores se utilizam do pagamento dos dividendos para sinalizar o desempenho atual e futuro da firma, de tal forma que o aumento nos dividendos sinaliza melhores condições para a empresa e a redução dos dividendos sinaliza más condições.

A teoria da agência, cujos precursores são Jensen e Meckling (1976), determina que em um ambiente corporativo a relação entre os agentes da firma leva a conflitos de agência que podem influenciar negativamente nas atividades da corporação e gerar custos adicionais, levando por consequência a perda de valor da firma. As causas destes conflitos estão associadas aos distintos interesses dos agentes e são agravados pela assimetria informacional.

Uma das formas de minimizar os conflitos de agência e a assimetria informacional seria através do aumento do pagamento de dividendos. Desta forma, os agentes internos (acionistas majoritários e administradores) vão ter menos recursos para atender seus próprios interesses e os agentes externos (acionistas e minoritários) vão receber por seus investimentos, o que por consequência aumentará o valor da empresa (NOVIS NETO; SAITO, 2003; LOSS; SARLO NETO, 2003).

Por fim, a teoria da sinalização proposta por Ramasastry, Kose e Williams (1987) defende que os gestores se utilizam da política de dividendos como um conteúdo informacional que sinaliza ao mercado sobre seu desempenho financeiro atual e futuro. Logo, uma maior distribuição de dividendos sinaliza de forma positiva ao mercado expectativas de crescimento da empresa (NISSIN; ZIV, 2001; LOSS; SARLO NETO, 2003; CIOFFI; FAMÁ, 2010).

Utilizando da teoria da sinalização, Boldin e Leggett (1995) buscaram analisar a gestão da política de dividendos de holdings bancárias americanas e evidenciar a importância dos dividendos como sinalizador de qualidade para o mercado financeiro. Foram analisadas 207 holdings bancárias americanas em dezembro de 1989. A metodologia adotada para tabulação dos dados foi a regressão ordenada Probit, que considerou as seguintes variáveis: dividendo por ação, dividendos dividido pelo lucro, tamanho, crescimento do ativo e rating. Os resultados evidenciaram que a política de dividendos produz informações sobre a qualidade dos bancos, já que há uma relação positiva entre os dividendos por ação e o rating dos bancos, o que é favorável à teoria da sinalização. Encontrou-se ainda uma relação inversa entre o pagamento dos dividendos e sua qualidade, o que pode ser atribuído ao maior risco assumido pela empresa pela alta taxa de retorno de dividendos, já que terá que considerar outras fontes de financiamento.

Khieu e Pyles (2016) pesquisaram a influência de mudanças no rating de crédito das empresas em suas políticas de dividendos e investimentos. Os autores encontraram que existe uma persistência no 
pagamento de dividendos mesmo quando as empresas sofrem uma redução em sua classificação de crédito, enquanto que seus investimentos declinam diante da redução do rating, indicando uma relação importante dos dividendos com uma possível manutenção de seu rating e de sinalização ao mercado da situação financeira das empresas.

Apesar de alguns autores encontrarem resultados favoráveis à teoria da sinalização, não há um consenso em seus resultados. Fiorati, Garcia e Tambosi Filho (2007) e Figueiredo (2002), por exemplo, não encontraram evidências para esta teoria, deixando claro que não há um consenso quanto à sinalização dos dividendos. Fiorati, Garcia e Tambosi Filho (2007) buscaram evidenciar a sinalização dos dividendos quanto a lucratividade futura da empresa para o mercado. Como resultado não encontrou relevância nesta relação. Figueiredo (2002), por sua vez, investigou a relação entre alterações de dividendos e mudanças de ganhos futuros em empresas brasileiras, no período de 1986 a 2000. Os resultados também não fornecem evidências que suportem a hipótese do conteúdo informativo de dividendos com o desempenho futuro das empresas, no período estudado.

No Brasil, as pesquisas realizadas indicam a predominância da relevância de dividendos no valor das empresas, segundo Martins e Famá (2012). Os estudos sobre os fatores relacionados ao pagamento de dividendos estão sendo atualizados e evoluindo em termos teóricos e empíricos, como os trabalhos conduzidos por Heineberg e Procianoy (2003), Forti, Peixoto e Alves (2015), Vancin e Procianoy (2016), Galvão, Santos e Araújo (2018) e Galvão, Santos e Araújo (2019). Este último, com uma amostra de 287 empresas brasileiras entre 2002 e 2014 encontrou que as empresas maiores, mais maduras, com mais caixa e com maiores oportunidades de crescimento pagavam mais dividendos enquanto as que possuíam maiores dívidas, pagam menos dividendos.

\subsection{Agências de rating e o rating de crédito}

As agências de rating são empresas independentes de quaisquer interesses que avaliam a capacidade e a determinação de uma empresa ou governo em honrar os seus compromissos financeiros dentro do prazo. Para este trabalho, considerar-se-á apenas a avaliação de risco dada por estas agências às empresas e que é denominada de rating corporativo (DAMASCENO; ARTES; MINARDI, 2008; XIA, 2014; SILVEIRA; TAKAMATSU; AVELINO, 2017).

O rating corporativo é um índice que opina sobre a capacidade de pagamento de empresas emitentes de dívida a longo prazo (BONE, 2006; MATSUMOTO et al., 2011). Por se referir a uma opinião sobre a qualidade de crédito de uma empresa, o rating corporativo não expressa uma verdade absoluta. Isto vai ao encontro à afirmação das próprias agências de rating que dizem que o mesmo não é uma avaliação genérica ou global do risco de crédito associado a todas as dívidas contraídas pelo emissor, mas à apenas uma específica, logo não é uma recomendação de investimento (REDDY, 2000; XIA, 2014).

A atribuição do rating da firma é feita por um comitê especializado dentro da agência, que desenvolve sua própria metodologia e critérios de avaliação, já que não existe um órgão regulador que os padronize. Os critérios estão em constante inovação para acompanhar as exigências do mercado, mas são constantes alvos de críticas em sua utilidade (DAMASCENO; ARTES; MINARDI, 2008; XIA, 2014).

Figura 2 - Resultados de Martins e Famá (2012)

\begin{tabular}{|c|c|c|}
\hline Grupo & Principal Objetivo & Resultados \\
\hline 1 & Teoria da Agência & $\begin{array}{l}\text { Os estudos vêm ao encontro com a teoria da agência, reforçando o } \\
\text { conflito de interesses entre acionistas controladores e minoritários. }\end{array}$ \\
\hline 2 & $\begin{array}{l}\text { Assimetria Informacional: } \\
\text { (a) Interação entre } \\
\text { investimentos e política de } \\
\text { dividendos; } \\
\text { (b) Hipótese da sinalização }\end{array}$ & $\begin{array}{l}\text { (a) Relação fraca entre política de dividendos e investimentos, devido } \\
\text { aos poucos estudos na área. } \\
\text { (b) Não há um consenso quanto a relação entre dividendos e sua } \\
\text { sinalização, pois três trabalhos encontraram uma forte relação entre eles } \\
\text { e oito trabalhos ou não encontraram esta relação, ou não conseguiram } \\
\text { encontrar esta relação. }\end{array}$ \\
\hline 3 & Hipótese da clientela & $\begin{array}{l}\text { Resultados conflitantes quanto a identificação do efeito clientela, o que } \\
\text { pode ser atribuído a necessidade de aperfeiçoamento dos métodos } \\
\text { aplicados, ou o mercado brasileiro não segue a mesma lógica da teoria. }\end{array}$ \\
\hline 4 & $\begin{array}{l}\text { fluência dos tributos na } \\
\text { lítica de dividendos } \\
\text { referência tributária) }\end{array}$ & $\begin{array}{l}\text { Não há um consenso entre acionistas minoritários e majoritários quanto } \\
\text { a melhor forma de distribuição dos resultados do ponto de vista } \\
\text { tributário. }\end{array}$ \\
\hline 5 & $\begin{array}{l}\text { Determinantes da política de } \\
\text { dividendos }\end{array}$ & $\begin{array}{l}\text { Determinantes que influenciam positivamente na distribuição de } \\
\text { dividendos: lucro líquido, fluxo de caixa, porte da empresa e menor } \\
\text { endividamento. Determinantes que influenciam negativamente o } \\
\text { pagamento dos dividendos: oportunidade de investimento e maior } \\
\text { concentração de propriedade nas mãos dos controladores. }\end{array}$ \\
\hline
\end{tabular}

Fonte: Adaptado de Martins e Famá (2012).

Um dos métodos adotados pelas agências para avaliar o rating corporativo é o Bottom-up, o qual parte do geral para o específico (BONE, 2006). Este método faz uma análise macroeconômica (ambiente 
econômico e político), setorial (grau de competitividade e market share no mercado global ao longo do tempo) e da própria empresa, avaliando neste último, informações quantitativas e qualitativas fornecidas pela própria administração. No que diz respeito à informação quantitativa, avalia as análises financeiras disponíveis nos Balanços Patrimoniais e Demonstrações Financeiras. No que diz respeito à informação qualitativa avalia a qualidade da gestão, perspectivas de crescimento, vulnerabilidade frente às mudanças tecnológicas, distúrbios no mercado de trabalho e ações regulatórias (MATSUMOTO et al., 2011).

Feita a análise das informações da empresa pelos especialistas, ela recebe uma classificação na escala de rating das agências, que não é estática, já que anualmente esta classificação é revisada pelas agências baseada em novos relatórios financeiros, novas informações de negócios e reuniões de acompanhamento com a administração (DAMASCENO; ARTES; MINARDI, 2008). Apesar de cada agência de rating ter sua própria escala com notações distintas, já que não há um órgão regulador, as classificações são semelhantes, sendo uma combinação de letras, algarismos e sinais. Além disso, os ratings dividem-se em três categorias: grau de investimento, grau especulativo e grau de default ou Junk Bond (KHIEU; PYLES, 2016).

Damasceno, Artes e Minardi (2008) apresentam um quadro comparativo com as diferentes classificações de rating adotadas pelas principais agências, dividindo as em 21 níveis e mostrando a interpretação de cada um deles, conforme segue na Figura 3. O presente trabalho considerou os mesmos níveis em sua metodologia para transformar os ratings a níveis.

Figura 3 - Classificação de rating pelas principais agências e sua interpretação

\begin{tabular}{|c|c|c|c|c|c|}
\hline \multicolumn{3}{|c|}{ Grau de Investimento } & \multicolumn{3}{|c|}{ Grau Especulativo } \\
\hline $\begin{array}{c}\text { S\&P e } \\
\text { outras } \\
\text { Agências }\end{array}$ & Moody's & Interpretação & $\begin{array}{c}\text { S\&P e } \\
\text { outras } \\
\text { Agências }\end{array}$ & Moody's & Interpretação \\
\hline AAA & Aaa & $\begin{array}{l}\text { Altíssima qualidade, com } \\
\text { mínimo risco de crédito. A } \\
\text { capacidade de pagamento } \\
\text { dos compromissos é } \\
\text { extremamente forte }\end{array}$ & $\begin{array}{l}\mathrm{BB}+ \\
\mathrm{BB} \\
\mathrm{BB}-\end{array}$ & $\begin{array}{l}\text { Ba1 } \\
\text { Ba2 } \\
\text { Ba3 }\end{array}$ & $\begin{array}{l}\text { Elementos especulativos e sujeitos a } \\
\text { risco de crédito substancial. Menos } \\
\text { vulneráveis do que outras emissões } \\
\text { especulativas. Entretanto, em face de } \\
\text { maior incerteza ou exposição a } \\
\text { adversidades financeiras, } \\
\text { econômicas e de negócios, podem } \\
\text { levar a uma capacidade inadequada } \\
\text { de pagamento. }\end{array}$ \\
\hline $\begin{array}{l}\mathrm{AA}+ \\
\mathrm{AA} \\
\mathrm{AA}-\end{array}$ & $\begin{array}{l}\text { Aa1 } \\
\text { Aa2 } \\
\text { Aa3 }\end{array}$ & $\begin{array}{l}\text { Alta qualidade, com risco de } \\
\text { crédito muito baixo. A } \\
\text { capacidade de pagamento } \\
\text { dos compromissos é muito } \\
\text { forte. }\end{array}$ & $\begin{array}{l}\mathrm{B}+ \\
\mathrm{B} \\
\mathrm{B}-\end{array}$ & $\begin{array}{l}\text { B1 } \\
\text { B2 } \\
\text { B3 }\end{array}$ & $\begin{array}{l}\text { Especulativo e sujeito a alto risco de } \\
\text { crédito. Condições econômicas, } \\
\text { financeiras e de negócios adversas } \\
\text { provavelmente prejudicarão a } \\
\text { capacidade ou a disposição de } \\
\text { pagamento de compromissos. }\end{array}$ \\
\hline $\begin{array}{c}A+ \\
A \\
A-\end{array}$ & $\begin{array}{l}\text { A1 } \\
\text { A2 } \\
\text { A3 }\end{array}$ & $\begin{array}{l}\text { Grau mediano e sujeito a } \\
\text { baixo risco de crédito. Um } \\
\text { pouco mais suscetível a } \\
\text { efeitos adversos de } \\
\text { mudanças nas } \\
\text { circunstâncias e nas } \\
\text { condições econômicas do } \\
\text { que obrigações de ratings } \\
\text { mais elevadas. Entretanto, a } \\
\text { capacidade de pagamento } \\
\text { dos compromissos ainda é } \\
\text { forte. }\end{array}$ & $\begin{array}{l}\mathrm{CCC}+ \\
\mathrm{CCC} \\
\mathrm{CCC}- \\
\mathrm{CC}\end{array}$ & $\begin{array}{c}\text { Caa1 } \\
\text { Caa2 } \\
\text { Caa3 } \\
\text { Ca }\end{array}$ & $\begin{array}{l}\text { Crédito pobre sujeito a alto risco de } \\
\text { crédito. Vulnerável a defaults e } \\
\text { dependente de condições financeiras, } \\
\text { econômicas e de negócios favoráveis } \\
\text { para o pagamento de suas } \\
\text { obrigações. Em condições } \\
\text { econômicas, financeiras e de } \\
\text { negócios adversas provavelmente } \\
\text { não terá capacidade de pagamento. }\end{array}$ \\
\hline \multirow[t]{2}{*}{$\begin{array}{l}\text { BBB+ } \\
\text { BBB } \\
\text { BBB- }\end{array}$} & $\begin{array}{l}\text { Baa1 } \\
\text { Baa2 } \\
\text { Baa3 }\end{array}$ & $\begin{array}{l}\text { Risco de crédito moderado. } \\
\text { É considerado um rating de } \\
\text { grau médio, com parâmetros } \\
\text { de proteção adequados. } \\
\text { Entretanto condições } \\
\text { econômicas adversas ou } \\
\text { mudança de circunstâncias } \\
\text { podem conduzir a um } \\
\text { enfraquecimento na } \\
\text { capacidade de pagamento } \\
\text { dos compromissos. }\end{array}$ & C & $\mathrm{C}$ & $\begin{array}{l}\text { Tipicamente em default, com baixa } \\
\text { possibilidade de recuperação do } \\
\text { principal ou juros. Pedidos de falência } \\
\text { ou outras ações similares têm sido } \\
\text { solicitados, mas os pagamentos das } \\
\text { obrigações ainda estão sendo } \\
\text { efetuados. }\end{array}$ \\
\hline & & & D & & Default \\
\hline
\end{tabular}

Fonte: Damasceno, Artes e Minardi (2008, p.3). 


\subsubsection{Importância dos ratings}

Os ratings, para Neves Junior, Matsumoto e Araujo (2007), tem caráter essencialmente informacional. Bone (2006), Matsumoto et al. (2011) e Khieu e Pyles (2016) concordam com os autores nesta questão e ainda consideram que as informações concedidas e divulgadas pelas agências de rating são relevantes e de interesse para investidores, emissores, intermediários e mercado como um todo. Para eles os ratings são sinalizadores de informações públicas e privilegiadas sobre os emitentes de dívida e, portanto, qualificam as emissões de crédito das empresas e medem os riscos de investimento, o que contribui para tomada de decisões dos investidores.

Reddy (2000) menciona que existe uma relação de interdependência entre as agências de rating e o mercado de investimento. Isto pode ser percebido nos estudos de Matsumoto et al. (2011) que encontraram em seus resultados de pesquisa uma relação positiva entre o rating e a falência das empresas, sendo que a medida que uma empresa se rebaixa nos índices classificatórios de rating, ela assume maior posição de desconfiança por parte dos investidores, e à medida que a nota do índice se eleva a confiança dos investidores aumenta.

Outros fatores que tornam relevante a existência das agências de rating para os investidores, segundo Bone (2006) e Matsumoto et al. (2011), são:

a) As agências de rating conseguem ter acesso a informações privilegiadas e estratégicas que os investidores individualmente não conseguiriam obter;

b) A forma sintética e simplória com que são classificados os ratings permite a um maior número de investidores interpretarem os dados que se tornam comparáveis, favorecendo-os e aos potenciais investidores;

c) Menor custo aos investidores para se analisar e controlar as informações obtidas pelo rating, uma vez que antes este custo era rateado entre vários interessados nessa informação e agora é financiado pela própria empresa.

Partnoy (2001), ao contrário, apresentou críticas às agências alegando que os ratings não são informativos, eles existem apenas por questões regulatórias e refletem o risco de mercado. Logo, os ratings não possuem a capacidade de antever crises e ainda agravam as já existentes, potencializando o risco dos investidores. Os fatores que tornam os ratings não confiáveis são:

a) Não regulamentação das agências de rating, o que impede a transparência por parte das agências quanto a sua ética e procedimentos de avaliação. Impede ainda sua responsabilidade e punição por eventuais danos causados aos investidores ou mesmo ao mercado. Exemplo desta impunidade foram os escândalos contábeis em empresas multinacionais, como a Enron, e instituições bancárias que eram avaliadas por estas agências, cuja avaliação não previu a crise financeira destas firmas (REDDY, 2000; BONE, 2006).

b) Conflito de interesses na estrutura de negócios das agências que é provocado pelo pagamento dos próprios emissores às agências de rating pelos serviços de emissão do rating. Sendo assim, surge a tendência de as agências atribuírem boas classificações para as empresas e hesitar em rebaixar sua nota quando necessário, a fim de não perder seu cliente (REDDY, 2000).

c) Dificuldade em monitorar a evolução das empresas pelas agências de rating, já que não possuem tempo e condições de bancar os custos para acompanhar a evolução das empresas (REDDY, 2000).

A partir do exposto, pode-se avaliar a relação entre a distribuição de dividendos e a classificação de rating das empresas listadas na B3 de 1995 a 2017, baseando nos aspectos da teoria da sinalização dos dividendos e investigar se o rating de crédito atua de forma complementar aos dividendos em conteúdo informativo ao mercado e investidores.

\section{Metodologia}

O período estudado compreende os anos de 1995 a 2017. Inicia-se em 1995, pois foi o ano de adoção do Plano Real no Brasil o qual trouxe maior estabilidade econômica ao país, permitindo maior comparabilidade dos dados coletados. Para atender ao problema de pesquisa, os dados foram coletados nas bases da Thomson Reuters e Economática. Na Thomson Reuters foram obtidos os ratings das empresas classificadas na B3 que são apresentados pelas principais agências (S\&P, Moody's e Fitch). Na Economática foram obtidos os demais dados, oriundos das principais demonstrações financeiras: Balanço Patrimonial e Demonstração do Resultado do Período.

Coletados os dados, foram excluídas as empresas que não apresentavam informações suficientes para a pesquisa. A amostra final ficou composta de 330 empresas, das quais 79 possuíam classificação de rating. Dividiu-se então a amostra em dois grupos com o intuito de fazer as análises necessárias para atender aos objetivos específicos deste trabalho. A primeira análise, denominada de Análise 1, considerou apenas as 
79 empresas com classificação de rating e testou-se a hipótese de que as empresas que tem maior rating distribuem mais dividendos. A segunda análise, denominada de Análise 2, incluiu as 330 empresas da amostra e procurou identificar se as empresas que tem rating distribuem mais ou menos dividendos se comparadas com as que não tem essa informação. A terceira análise, denominada de Análise 3 , consiste em um teste de robustez da Análise 2 e testa se há diferença entre as empresas que possuem e não possuem rating utilizando o propensity score e matching estimators.

\section{Figura 4 - Escala de rating por classificação de rating}

\begin{tabular}{cccccc}
\hline \multicolumn{7}{c}{ Grau de Investimento } & \multicolumn{3}{c}{ Escala de Rating } & Grau Especulativo \\
\hline S\&P e Fitch & Moody's & Classificação & S\&P e Fitch & Moody's & Classificação \\
\hline AAA & Aaa & 21 & BB+ & Ba1 & 11 \\
AA+ & Aa1 & 20 & BB & Ba2 & 10 \\
AA & Aa2 & 19 & BB- & Ba3 & 9 \\
AA- & Aa3 & 18 & B+ & B1 & 8 \\
A+ & A1 & 17 & B & B2 & 7 \\
A & A2 & 16 & B- & B3 & 6 \\
A- & A3 & 15 & CCC+ & Caa1 & 5 \\
BBB+ & Baa1 & 14 & CCC & Caa2 & 4 \\
BBB & Baa2 & 13 & CCC - & Caa3 & 3 \\
BBB- & Baa3 & 12 & CC & Ca & 2 \\
& & & C & C & 1 \\
\hline
\end{tabular}

Fonte: Elaborado pelos autores.

Para realizar a Análise 1, adotou-se metodologia similar à de Boldin e Leggett (1995) que atribuiu à classificação de rating das empresas uma nota. O objetivo foi unificar os diferentes níveis de classificação adotados pelas agências em uma escala, de forma a permitir seu uso em regressões. Como cada agência apresenta um tipo de classificação diferente, adotaram-se os 21 níveis de rating propostos por Damasceno, Artes e Minardi (2008), conforme Figura 3 deste trabalho. Desta forma, a escala de rating adotada nesta pesquisa vai de 0 (zero) a 21, sendo atribuída nota 0 (zero) a menor classificação (D) e nota 21 a maior classificação (AAA). Além disso, utilizou-se de média aritmética para as empresas que apresentavam classificação de rating em mais de uma agência no mesmo período. A Figura 4 evidencia a nota de cada classificação de rating para as diferentes agências.

As variáveis adotadas nesta pesquisa, seguindo Forti, Peixoto e Alves (2015), são aquelas utilizadas na literatura sobre política de dividendos: variável dependente - dividendos divididos pelo Patrimônio Líquido $(\mathrm{PL})$, e variáveis de controle: Tamanho da empresa, Retorno sobre o Ativo (ROA), Alavancagem e Crescimento dos Lucros.

A variável dependente foi padronizada pelo PL ao invés dos lucros por um motivo importante: os lucros possuem uma variação acentuada entre os anos enquanto que os dividendos são mais constantes, segundo os estudos de Lintner (1956), portanto a variável dependente sofreria variações causadas pela variação dos lucros e não por uma variação dos dividendos. Assim, seguindo a metodologia de Forti, Peixoto e Alves (2015) os dividendos foram padronizados pelo PL para assegurar uma maior constância em seus valores e para que sua variação reflita mudanças efetivas nos dividendos, e não sejam influenciadas por variações naturais nos lucros das empresas. Além disso, podem ocorrer pagamentos de dividendos mesmo quando a empresa incorre em prejuízo no período.

Os trabalhos que utilizam o payout (Dividendos/Lucro Líquido) são forçados a excluir todas estas observações, devido à inversão do sinal. Nossa base de dados possui 146 empresas que em algum momento pagaram dividendos mesmo incorrendo em prejuízos no exercício contábil. A Figura 5 apresenta a descrição das variáveis utilizadas, bem como o sinal esperado e sua influência sobre os dividendos.

Os métodos estatísticos adotados para a análise foram regressões múltiplas com dados em painel, seguindo Baltagi (2005), Cameron e Trivedi (2005) e Wooldrigde (2002). Com o uso do software Stata, os coeficientes foram estimados em três diferentes métodos para dar maior robustez ao trabalho: Pooled OLS (OLS), Tobit e GMM.

O Pooled OLS com a opção de tratamento de erros robustos é um modelo tradicionalmente utilizado em política de dividendos, no entanto apresenta algumas limitações como não levar em consideração a natureza de cada cross-section ao longo do tempo. Além disso, a amostra de empresas nem sempre atende aos pressupostos básicos do modelo, visto que os dividendos apresentam uma distribuição assimétrica devido a elevada incidência de observações iguais a zero. Desta forma, o uso do método Tobit, segundo Barclay, Smith e Watts (1995) e Dickens, Casey e Newman (2002), mostra-se mais adequado já que os dividendos apresentam extremidade inferior limitada ou censurada em zero.

Além disso, estimadores OLS e de efeitos fixos (ou aleatórios) possuem como pressuposto central a exogeneidade estrita dos regressores, ou seja, as variáveis independentes não podem ser correlacionadas como o termo de erro do modelo em nenhum dos períodos (BALTAGI, 2005; ROODMAN, 2009). Entretanto, 
esse pressuposto é difícil de ser atendido em estudos de finanças corporativas que adotam dados de diferentes empresas em diferentes períodos de tempo, devido às potenciais fontes de endogeneidade nas relações entre as variáveis (BARROS et al., 2010).

Figura 5 - Variáveis da pesquisa

\begin{tabular}{|c|c|c|c|}
\hline Variáveis & $\begin{array}{c}\text { Sinal } \\
\text { Esperado }\end{array}$ & Definição Operacional & Influência sobre os dividendos \\
\hline Dividendos/PL & & $\begin{array}{l}\text { Soma dos Dividendos e } \\
\text { dos Juros sobre o Capital } \\
\text { Próprio divididos pelo }\end{array}$ & $\begin{array}{l}\text { Esta é a variável dependente. Representa a } \\
\text { proporção do patrimônio líquido que foi distribuída } \\
\text { aos acionistas. }\end{array}$ \\
\hline
\end{tabular}

$\begin{array}{lll}\begin{array}{l}\text { Tamanho da } \\ \text { empresa }\end{array} & (+) & \begin{array}{l}\text { Logaritmo natural do Ativo } \\ \text { Total da empresa. }\end{array}\end{array}$

\begin{tabular}{lll}
\hline ROA & $(+)$ & $\begin{array}{l}\text { Lucro Operacional (antes } \\
\text { das despesas financeiras) } \\
\text { dividido pelo Ativo Total. }\end{array}$ \\
\hline Alavancagem & $(+/-)$ & $\begin{array}{l}\text { Passivo Oneroso dividido } \\
\text { pelo Patrimônio Líquido. }\end{array}$
\end{tabular}
Espera-se que empresas maiores tenham maior propensão a pagar dividendos do que empresas menores.
Espera-se que as empresas mais lucrativas paguem mais dividendos do que as demais.

\begin{abstract}
A literatura de finanças normalmente associa a relação entre dividendos e alavancagem a um efeito de sinalização. Um aumento nos níveis de endividamento da empresa seria um sinal crível de que a empresa espera um fluxo de caixa futuro elevado. Neste contexto, os gestores deveriam pagar mais dividendos para confirmar tal sinal. Em outra linha de pesquisa, o nível de endividamento da empresa poderia restringir a sua capacidade de pagar dividendos fazendo com que a empresa seja obrigada a reduzir seus níveis de dividendos. Assim, o sinal esperado para alavancagem constitui-se em um problema empírico e que não pode ser conhecido de forma antecipada.
\end{abstract}

\begin{tabular}{lll}
\hline Crescimento dos & $(+)$ & Espera-se que empresas com elevadas taxas de \\
lucros & & crescimento dos lucros distribuam mais dividendos, \\
& já que há menos incerteza por parte dos gestores \\
& quanto ao fluxo futuro de caixa.
\end{tabular}

Fonte: Adaptado de Forti, Peixoto e Alves (2015).

No contexto da distribuição de dividendos, os estudos existentes exploram principalmente as ligações diretas entre dividendos, desempenho, endividamento e investimento, ignorando os problemas de endogeneidade. Os fatores observáveis e não observáveis que influenciam os dividendos também podem ter impacto em suas políticas e em algumas outras características específicas da empresa, tais como crescimento, endividamento e investimentos, bem como é provável que as relações entre a política de investimentos e as características específicas da empresa reflitam nas políticas de dividendos da empresa e vice-versa.

Portanto, os modelos de análise de políticas de dividendos, possuem uma implicação metodológica que precisa ser levada em consideração: o modelo examina concomitantemente os efeitos de ambos os mecanismos de dividendos, investimento e endividamento, o que pode resultar em associações endógenas (BARROS et al., 2010). Assim, segundo os autores, a estimação dos modelos com regressores endógenos pode resultar em inferências equivocadas, pois essa condição entre as variáveis introduz um viés nos estimadores que ignoram o problema ou os torna inconsistentes. A endogenia pode derivar de problemas como omissão de variáveis, erros de mensuração dos regressores e/ou simultaneidade.

A omissão de variáveis é apontada como a causa mais comum de endogenia. Ocorre quando se pretende controlar determinadas variáveis, mas em decorrência da ausência de dados ou indisponibilidade dos mesmos, elas não podem ser incluídas no modelo, e quando não incluídas elas compõem o termo de erro, induzindo alguma correlação entre $X_{i}$ e $\varepsilon_{i}$. Já a simultaneidade ou causalidade reversa ocorre quando na relação entre $\mathrm{X}$ e $\mathrm{Y}$, ambas podem ser consideradas variáveis explicativas ou explicadas, uma em relação à outra (BARROS et al., 2010; WOOLDRIGE, 2002).

Em teoria, para solucionar a endogeneidade seria preciso encontrar variáveis estritamente exógenas para cada um dos regressores suspeitos de endogenia, porém, na prática variáveis com essa característica e que ainda possuem alta correlação com os regressores são quase impossíveis de serem encontradas em estudos na área de finanças corporativas (CAMERON; TRIVEDI, 2005; BARROS et al., 2010). Essas variáveis são também chamadas de Variáveis Instrumentais.

Segundo Roodman (2009) e Barros et al. (2010) os estimadores baseados no Método dos Momentos Generalizado (GMM) quando aplicados a dados em painel consistem em alternativas eficazes e eficientes para eliminar, ou ao menos mitigar, os problemas de endogenia encontrados na área de finanças corporativas, por meio da suposição de exogeneidade sequencial dos regressores, ainda que não se disponha de bons 
instrumentos que sejam exógenos ao modelo.

Assim, a fim de superar as limitações dos modelos tradicionais de dados em painel, controlar a presença de efeitos específicos das empresas não observados e os potenciais problemas de endogeneidade das variáveis, o presente estudo empregará o Método dos Momentos Generalizados Sistêmico (GMM Sistêmico) para avaliar a relação entre a política de dividendos, o rating de crédito das empresas e suas variáveis de controle, como Tamanho, Endividamento, Crescimento e Desempenho.

Com o objetivo de atender as Análises 1 e 2 deste trabalho, foram adotados dois modelos econométricos. Para a Análise 1, foi adotado o seguinte modelo:

Dividendos $_{i, t}=\alpha+$ Rating $_{i, t}+$ Tamanho $_{i, t}+R O A_{i, t}+$ Alavancagem $_{i, t}+$ Crescimento dos Lucros $_{i, t}+d_{t}+\varepsilon_{i, t}$

Onde $i$ e $t$ representam a empresa e $o$ ano, respectivamente, e $\alpha, d$ e $\varepsilon$ representam o intercepto, dummies de ano e o termo de erro, respectivamente. As variáveis dummies de ano foram adicionadas ao modelo para controlar as características específicas de cada ano que não podem ser medidas diretamente por outra variável específica.

A Análise 2, de forma complementar à Análise 1, incluiu em seu modelo econométrico uma dummy que atribui valor igual a 1 para as empresas que têm rating e 0 (zero) para as que não têm. Segue o modelo desta análise:

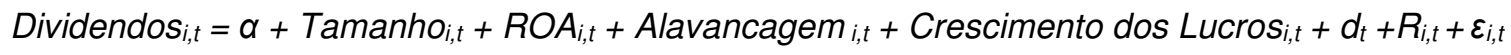

Onde $i$ e $t$ representam a empresa e $o$ ano, respectivamente e $\alpha, d, R$ e $\varepsilon$ representam o intercepto, dummies de ano, dummy possui rating e o termo de erro, respectivamente.

A Análise 3 consiste em um teste de robustez da Análise 2. Nesta análise foi adotado o método de Propensity Score Matching ou pareamento de Rosenbaum e Rubin (1983). Neste método é possível comparar o resultado (pagamento de dividendos) de dois indivíduos (empresas) similares sendo que um deles foi tratado (possui rating) e o outro não foi tratado (não possui rating). Neste método, o software estatístico (Stata) separa as empresas em tratadas (com rating) e controle (sem rating). Em seguida são encontrados pares (Matching) de empresas de cada um dos grupos, de modo que estas empresas sejam o mais parecidas o possível exceto pelo fato de que uma possui rating e a outra não possui. O método de pareamento utilizado neste trabalho é conhecido como Propensity Score Matching de Rosenbaum e Rubin (1983) onde se constrói os pares baseando-se em características observáveis, neste caso as variáveis de controle (tamanho, endividamento, crescimento dos lucros e ROA).

A partir da definição dos pares, os pagamentos de dividendos são comparados a cada par, resultando assim em uma comparação adequada entre empresas com as mesmas características (observáveis) e apenas diferentes no aspecto de possuir ou não uma classificação de crédito. Desta forma a Análise 3 suporta os resultados da Análise 2, sob uma metodologia alternativa e mais robusta para inferências de causa e efeito.

Ressalta-se que todos os métodos aplicados neste trabalho foram precedidos dos testes necessários para a utilização de cada um. Portanto foram efetuados testes e correções para multicolinearidade, heterocedasticidade, normalidade dos resíduos e especificação. Para o GMM foram realizados testes específicos como teste de raiz unitária, autocorrelação de Arellano-Bond e exogeneidade dos instrumentos.

\section{Resultados}

Os resultados das regressões para as análises 1,2 e 3 mencionadas na metodologia foram apresentados em três subtópicos para facilitar a compreensão. O subtópico 4.1 apresenta o resultado das regressões com as 79 empresas que têm rating, o subtópico 4.2, o resultado das regressões com todas as 330 empresas da amostra e o subtópico 4.3, o teste de robustez.

\subsection{Resultados da Análise 1}

A Tabela 1 apresenta a análise das regressões para as empresas da amostra que têm rating. Podese perceber, que independente dos estimadores utilizados (Pooled-OLS, Tobit e GMM) os coeficientes são consistentes em significância e no seu sinal. Nenhum apresentou diferença de sinal ou de significância estatística relevante. Acredita-se que o GMM seja o mais eficiente e consistente em termos de exatidão nos resultados. As variáveis Rating, ROA e Alavancagem, mostraram-se, ceteris paribus, positivas e significantes. A variável Tamanho também se mostrou positiva nos três modelos, mas significante apenas no modelo GMM. O sinal positivo evidencia a influência positiva da variável sobre um maior pagamento de dividendos. A variável Crescimento dos Lucros mostrou-se insignificante estatisticamente nesta amostra.

O Tamanho mostrou-se positivo, indicando que quanto maior a empresa maior a propensão em se pagar dividendos. No entanto, só há coeficiente de significância para esta variável no modelo GMM, o que pode ser atribuído ao tamanho da amostra. O sinal encontrado está condizente com o esperado para esta variável na literatura (MARTINS; FAMÁ, 2012; FORTI; PEIXOTO; ALVES, 2015; GALVÃO; SANTOS; 
ARAÚJO, 2019). Isto indica que empresas maiores possuem maior capacidade de pagamento ou mais maturidade em seus fluxos de caixa.

O ROA, conforme esperado, mostrou-se positivo e significante em todos os modelos, evidenciando que a distribuição de dividendos está diretamente relacionada com a rentabilidade da empresa. Reforça, portanto, os estudos de Lintner (1956), deixando ainda mais clara a teoria de que quanto mais rentável a empresa maior a expectativa dos acionistas quanto ao recebimento dos dividendos.

Apesar de não haver na literatura um consenso sobre o comportamento da variável Alavancagem, nos resultados desta amostra mostrou-se positiva e significante, ou seja, quanto mais alavancada maior a distribuição de dividendos. Contraria os estudos dos fatores que influenciam a política de dividendos no Brasil, como Martins e Famá (2012), Forti, Peixoto e Alves (2015) e Galvão, Santos e Araújo (2019) que defendem uma relação negativa entre dividendos e alavancagem, de forma que quanto menos alavancada maior a distribuição dos dividendos. Contudo confirma a Teoria da Sinalização dos dividendos (BHATTACHARYA,1979; NISSIM; ZIV, 2001) pois se a empresa possui mais dívidas e paga mais dividendos, significa que ela espera um fluxo de caixa futuro elevado de seus investimentos. Confirma também a teoria da redução de assimetrias informacionais já que empresas com maior dependência de credores pagam mais dividendos (SHAO et al., 2013; ASHRAF; ZHENG, 2015; CHANG et al., 2018).

O Crescimento dos Lucros mostrou-se negativo em dois modelos e positivo em um, no entanto, não há um nível de significância nesta análise, mostrando que esta variável tende a ser zero, ou seja, não influencia na distribuição dos dividendos. Este resultado pode ser atribuído à amostra pequena obtida para esta análise, o que não permitiu que seu resultado fosse condizente com a literatura, a qual espera um sinal positivo para esta variável, de forma que sinalize ao mercado que quanto maior a taxa de crescimento de lucros maior a distribuição de dividendos (LINTNER, 1956).

Por fim, a variável de interesse, Rating, mostrou-se positiva e significante, o que evidencia que quanto maior o rating maior o pagamento de dividendos. A relação significante é favorável ao papel sinalizador do rating ao mercado, conforme defendido por Neves Junior, Matsumoto e Araujo (2007), Matsumoto et al. (2011), Forti e Schiozer (2015), Boldin e Leggett (1995) e Khieu e Pyles (2016). O resultado é relevante pois o estudo controla os efeitos do endividamento e do tamanho da empresa, que poderiam ser apontados como inferências alternativas para a variável de rating. A versão de que empresas que possuem rating seriam maiores ou possuem maior necessidade de alavancagem e por isso possuem esta classificação, fica enfraquecida diante da robustez dos resultados e das variáveis de controle utilizadas.

Tabela 1 - Modelos de Regressão com as empresas com rating

\begin{tabular}{|c|c|c|c|c|}
\hline \multirow[t]{2}{*}{ Variável dependente } & \multirow[b]{2}{*}{$\begin{array}{c}\text { Sinal } \\
\text { Esperado }\end{array}$} & \multicolumn{3}{|c|}{ Dividendos/ Patrimônio Líquido } \\
\hline & & $\begin{array}{l}(1) \\
\text { OLS }\end{array}$ & $\begin{array}{c}\text { (2) } \\
\text { Tobit }\end{array}$ & $\begin{array}{c}\text { (3) } \\
\text { GMM-Sys }\end{array}$ \\
\hline Rating & $(+)$ & $\begin{array}{c}0.0062^{\star \star \star} \\
(4.14)\end{array}$ & $\begin{array}{c}0.0074^{\star \star \star} \\
(4.15)\end{array}$ & $\begin{array}{c}0.0061^{* *} \\
(4.81)\end{array}$ \\
\hline Tamanho & $(+)$ & $\begin{array}{c}0.0031 \\
(0.96)\end{array}$ & $\begin{array}{r}0.0061 \\
(1.57)\end{array}$ & $\begin{array}{c}0.0040^{*} \\
(1.70)\end{array}$ \\
\hline ROA & $(+)$ & $\begin{array}{c}0.2624^{\star \star *} \\
(5.40)\end{array}$ & $\begin{array}{c}0.3344^{* * *} \\
(6.11)\end{array}$ & $\begin{array}{c}0.2389^{\star \star \star \star} \\
(7.57)\end{array}$ \\
\hline Crescimento dos lucros & $(+)$ & $\begin{array}{c}-0.0006 \\
(-0.70)\end{array}$ & $\begin{array}{c}-0.0001 \\
(-0.09)\end{array}$ & $\begin{array}{c}0.0004 \\
(0.52)\end{array}$ \\
\hline Alavancagem & $(+/-)$ & $\begin{array}{c}0.0062^{\star * *} \\
(4.29)\end{array}$ & $\begin{array}{c}0.0067^{* \star *} \\
(4.28)\end{array}$ & $\begin{array}{c}0.0033^{\star \star \star} \\
(3.98)\end{array}$ \\
\hline Constante & & $\begin{array}{c}-0.0910^{*} \\
(-1.80)\end{array}$ & $\begin{array}{c}-0.1594^{\star * *} \\
(-2.69)\end{array}$ & $\begin{array}{c}-0.1234^{* \star \star} \\
(-3.31)\end{array}$ \\
\hline Dummy para Ano & & $\operatorname{Sim}$ & Sim & Sim \\
\hline Observações & & 559 & 559 & 559 \\
\hline $\begin{array}{l}\text { Número de empresas } \\
\mathrm{R}^{2}\end{array}$ & & 79 & 79 & 79 \\
\hline
\end{tabular}

Nota: Esta tabela apresenta regressões Pooled OLS (1), Tobit (2) e GMM (3) com dados em Painel. A variável dependente em todos os modelos é Dividendos dividido pelo Patrimônio Líquido. A amostra inclui as empresas listadas na B3 entre os anos de 1995 a 2017 e que possuem classificação de rating. Todos os modelos possuem variáveis dummy para o ano. Valores absolutos das estatísticas t para os coeficientes das variáveis independentes são apresentados em parênteses. Os níveis de significância são ${ }^{*} p<0.10,{ }^{* *} p<0.05,{ }^{* * *} p<0.01$.

Fonte: Elaborado pelos autores.

A análise 1, portanto, evidencia que, dentre as empresas que possuem classificação de rating, as empresas que tem um maior rating distribuem mais dividendos, conforme esperado na pesquisa. Isto pode ser atribuído ao fato dos gestores se utilizarem do maior pagamento dos dividendos para sinalizar ao mercado sobre suas boas expectativas futuras de fluxo de caixa e com isso conseguir melhores condições de financiamento, pois um melhor rating representa um custo menor das dívidas para a empresa. Encontra-se então uma vantagem do maior pagamento dos dividendos pelo menor custo das dívidas. Esta lógica é reforçada pelo sinal positivo da variável Alavancagem, que indica que empresas que pagam mais dividendos 
possuem mais dívidas. Logo, pelo conjunto das análises, nota-se uma relação positiva entre a distribuição de dividendos e a classificação de rating das empresas listadas na B3, em uma amostra composta apenas por empresas que possuem rating. $O$ resultado indica que dentre as empresas com rating, aquelas com melhor avaliação são as que pagam maiores dividendos a seus acionistas, evidenciando um fator sinalizador desta variável ao mercado.

\subsection{Resultados da Análise 2}

A Tabela 2 permite analisar, entre todas as empresas da amostra, se aquelas que têm classificação de rating distribuem mais ou menos dividendos do que aquelas que não têm esta classificação. Pode-se notar que as variáveis Tamanho, ROA, Alavancagem e Crescimento dos Lucros são positivas nos três modelos (OLS, Tobit e GMM), não apresentando esta última variável coeficiente de significância no modelo Tobit. Já a variável possui rating apresenta um valor negativo e significante nos três modelos.

ROA e Alavancagem obtiveram o mesmo sinal e significância dos valores encontrados na Tabela 1 , o que reforça a relação positiva destas variáveis com a distribuição dos dividendos. Sendo assim, quanto maior a rentabilidade e a alavancagem, maior a distribuição de dividendos. Conforme, já foi mencionada na Análise 1, a relação positiva entre $R O A$ e dividendos já era esperada pela literatura, no entanto a relação positiva com a variável Alavancagem reforça a corrente que, segundo Forti e Schiozer (2015), defendem que um aumento no endividamento sinaliza que a empresa espera um elevado fluxo futuro de caixa e então os gestores pagam mais dividendos para confirmar esta sinalização.

Tabela 2 - Modelos de regressão com todas as empresas da amostra

\begin{tabular}{|c|c|c|c|c|}
\hline \multirow[t]{2}{*}{ Variável dependente } & \multirow[b]{2}{*}{$\begin{array}{c}\text { Sinal } \\
\text { Esperado }\end{array}$} & \multicolumn{3}{|c|}{ Dividendos/ Patrimônio Líquido } \\
\hline & & $\begin{array}{l}(1) \\
\text { OLS }\end{array}$ & $\begin{array}{c}(2) \\
\text { Tobit }\end{array}$ & $\begin{array}{c}\text { (3) } \\
\text { GMM-Sys }\end{array}$ \\
\hline Possui rating & & $\begin{array}{c}-0.00168^{\star \star *} \\
(-4.69)\end{array}$ & $\begin{array}{c}-0.0206^{* * *} \\
(-4.79)\end{array}$ & $\begin{array}{c}-0.0328^{* * *} \\
(-10.19)\end{array}$ \\
\hline Tamanho & $(+)$ & $\begin{array}{c}0.0068^{\star \star \star} \\
(11.12)\end{array}$ & $\begin{array}{c}0.0147^{\star \star \star *} \\
(16.66)\end{array}$ & $\begin{array}{c}0.0089^{* \star *} \\
(20.80)\end{array}$ \\
\hline ROA & $(+)$ & $\begin{array}{c}0.1985^{\star * *} \\
(19.41)\end{array}$ & $\begin{array}{c}0.5012^{\star \star \star} \\
(23.07)\end{array}$ & $\begin{array}{c}0.1492^{\star \star \star} \\
(23.23)\end{array}$ \\
\hline Crescimento dos lucros & $(+)$ & $\begin{array}{c}0.0014^{* * *} \\
(4.65)\end{array}$ & $\begin{array}{c}0.0006 \\
(1.21)\end{array}$ & $\begin{array}{c}0.0013^{\star * *} \\
(5.88)\end{array}$ \\
\hline Alavancagem & $(+/-)$ & $\begin{array}{c}0.0021^{\star * *} \\
(6.07)\end{array}$ & $\begin{array}{c}0.0040^{\star \star *} \\
(7.50)\end{array}$ & $\begin{array}{c}0.0017^{\star * *} \\
(7.83)\end{array}$ \\
\hline Constante & & $\begin{array}{c}-0.0635^{\star \star *} \\
(-6.61)\end{array}$ & $\begin{array}{c}-0.1931^{\star * *} \\
(-13.42)\end{array}$ & $\begin{array}{c}-0.0928^{* * *} \\
(-12.22)\end{array}$ \\
\hline Dummy para ano & & Sim & Sim & Sim \\
\hline Observações & & 5079 & 5079 & 5079 \\
\hline Empresas & & 330 & 330 & 330 \\
\hline $\mathrm{R}^{2}$ & & 0.2457 & & \\
\hline
\end{tabular}

Nota: Esta tabela apresenta regressões Pooled OLS (1), Tobit com dados em Painel (2) e GMM (3). A variável dependente em todos os modelos é Payout dividido pelo Patrimônio Líquido. A amostra inclui todas as empresas listadas na B3 entre os anos de 1995 a 2017. Todos os modelos possuem variáveis dummy para o ano. Valores absolutos das estatísticas t para os coeficientes das variáveis independentes são apresentados em parênteses. Os níveis de significância são * $p<0.10,{ }^{* *} p<0.05,{ }^{* * *} p<0.01$.

Fonte: Elaborado pelos autores.

As variáveis Tamanho e Crescimento dos Lucros, apresentaram resultados condizentes com o esperado pela literatura, positivos e significantes. Sendo assim, a variável tamanho mostra que quanto maior e mais madura a empresa maior a distribuição dos dividendos, o que pode ser atribuído às reduções nas possibilidades de novos investimentos da empresa ou a facilidade de acesso a fontes alternativas de financiamentos, fazendo com que a firma retenha menos lucros para fazer os investimentos (MARTINS; FAMÁ, 2012; FORTI; PEIXOTO; ALVES, 2015). Já a variável Crescimento dos Lucros, evidencia que os gestores se utilizam dos dividendos para sinalizar sobre os lucros futuros, já que a variável rentabilidade já foi explorada na regressão. Isto reforça os estudos de Loss e Sarlo Neto (2003), Cioffi e Famá (2010), Novis Neto e Saito (2003), Correia e Amaral (2002).

Por fim, a variável possui rating tem relação negativa e significante com a distribuição de dividendos, de tal forma que as empresas com rating pagam menos dividendos. Isto pode indicar que estas empresas utilizam o rating como uma informação adicional ao mercado e com isso sinalizam menos por meio do pagamento de dividendos, o que pode ser vantajoso já que o custo de um rating é significativamente menor do que o custo do pagamento de dividendos. Esta análise, reforça a existência de uma relação de sinalização complementar entre a distribuição de dividendos e a classificação rating das empresas.

Portanto, constatou-se que as empresas que têm rating distribuem menos dividendos do que aquelas que não têm esta classificação, ou seja, quando analisadas a amostra de 330 empresas, incluindo empresas 
com e sem rating, as que não possuem classificação de rating distribuem mais dividendos do que aquelas que a têm. Tal resultado confirma a teoria de que os dividendos são utilizados como sinalizadores da saúde financeira da empresa e que o rating também sinaliza a mesma informação. Portanto empresas com rating podem pagar menos dividendos, uma vez que possuem as duas formas de sinalização enquanto empresas sem rating possuem apenas os dividendos para sinalizar sua situação financeira ao mercado.

\subsection{Resultados da Análise 3 - Teste de Robustez}

Esta análise foi desenvolvida com objetivo de complementar e trazer robustez aos resultados apresentados na análise 2. Mesmo com um modelo robusto em termos de endogeneidade como o GMM, inferências de causa e efeito devem ser apresentadas com cautela. Outro aspecto que deve ser considerado refere-se à abordagem do impacto dos dividendos mínimos obrigatórios conforme levantado por Vancin e Procianoy (2016).

Para isso desenvolveu-se uma análise com Propensity Score Matching usando a técnica ATT (Average Treatment Effect on the Treated). O modelo calcula a diferença entre tratados (com rating) e controle (sem rating) comparando empresas aos pares (Matching). A diferença encontrada entre o pagamento de dividendos de tratados e controle pode ser considerada robusta, pois somente compara empresas que são semelhantes exceto pelo fato de uma possuir rating e a outra não.

Tabela 3 - Diferença do pagamento de dividendos entre empresas com e sem rating de crédito

\begin{tabular}{lccccc}
\multicolumn{1}{c}{ ATT } & Tratados & Controle & Diferença & Erro Padrão & t \\
\hline Nearest Neighbor & 559 & 342 & $-0.021^{\star * *}$ & 0.008 & -2.60 \\
Kernel Matching & 559 & 2485 & $-0.008^{\star * *}$ & 0.004 & -1.96 \\
Stratification & 559 & 2485 & $-0.007^{\star *}$ & 0.003 & -2.00 \\
\hline
\end{tabular}

Nota: Diferença do pagamento de dividendos entre empresas com e sem rating de crédito. Empresas com rating foram alocadas no grupo de "tratados" e as empresas sem no grupo de "controle". Diferenças ATT calculadas por Propensity Score Matching pelos métodos de Nearest Neighbor, Kernel Matching e Stratification. A variável de interesse é Payout dividido pelo Patrimônio Líquido. A amostra inclui todas as empresas listadas na B3 entre os anos de 1995 a 2017. Os níveis de significância são ${ }^{*} p<0.10,{ }^{* *} p<0.05,{ }^{* * *} p<0.01$.

Fonte: Elaborado pelos autores.

Os resultados apresentados na Tabela 3 demonstram que qualquer que seja o método de pareamento utilizado, a diferença entre o pagamento de dividendos entre tradados e controle é estatisticamente significante a $1 \%$ e $5 \%$. Em resumo, empresas com classificação de rating, pagam menos dividendos do que empresas que não possuem, confirmando os resultados da Análise 2 através de uma técnica estatística robusta para causa e efeito. Empresas similares em suas características como endividamento, tamanho, ROA e crescimento dos lucros, mas diferentes apenas em possuir ou não classificação de crédito pagam dividendos diferentes em média, reforçando assim a afirmação de que dividendos são utilizados como sinalização e que o rating também sinaliza ao mercado, e assim, as empresas podem utilizar os dois como forma de sinalizar sua boa situação econômica e financeira.

Cabe pontuar que o resultado apresentado também mitiga o risco da influência dos DMO (VANCIN; PROCIANOY, 2016) nos resultados da Análise 2, pois o método de comparação entre pares de tratados e controle pressupõe que a única diferença entre as empresas seria a presença de classificação de rating.

\section{Considerações Finais}

O objetivo desta pesquisa foi identificar se os dividendos pagos pelas empresas possuem uma função complementar de sinalização ao mercado e/ou de redução de assimetria informacional com os credores das empresas (NISSIM; ZIV, 2001). Como estratégia de identificação, analisou-se a relação entre a distribuição de dividendos e a classificação de rating das empresas, de tal forma a identificar se há uma mudança consistente na política de dividendos de empresas que utilizam esta classificação, o que indica a sobreposição de funções entre os dois (BOLDIN; LEGGETT, 1995; KHIEU; PYLES, 2016). O modelo avaliou se dentre as empresas com esta classificação, as de maior rating distribuem mais dividendos, e se dentre todas as firmas, aquelas com classificação de rating distribuem menos dividendos do que as demais.

A estratégia de identificação utilizou dividendos como variável dependente e a classificação de rating como variável de interesse. Foram adotadas variáveis de controle para aspectos relevantes como Tamanho, Alavancagem, ROA e Crescimento dos Lucros, que são utilizadas na literatura de política de dividendos e que se comportaram, por meio dos estimadores Polled OLS, Tobit e GMM, condizentes com a literatura (MARTINS; FAMÁ, 2012; FORTI; PEIXOTO; ALVES, 2015; GALVÃO; SANTOS; ARAÚJO, 2019). Além disso, seus resultados permitiram concluir que o rating é utilizado pelas firmas como informação adicional de sinalização ao mercado e como redutora de assimetria com os credores (FORTI; SCHIOZER, 2015). Os estimadores dos coeficientes utilizados são adequados ao comportamento dos dividendos que possuem dados censurados em zero e problemas de endogeneidade das variáveis estudadas. 
Os resultados são consistentes com a hipótese de sinalização pois os gestores pagam mais dividendos ao mercado com o intuito de sinalizar suas boas perspectivas futuras de caixa e com isso conseguir melhores condições de financiamentos (NISSIM; ZIV, 2001). Este artigo apresenta novas evidências no sentido de que empresas utilizam do rating como uma informação adicional ao mercado e com isso sinalizam menos por meio do pagamento de dividendos, o que pode ser vantajoso já que o custo do rating é significantemente menor do que o custo do pagamento de dividendos superiores. Tal resultado confirma a teoria de que os dividendos são utilizados como sinalizadores da saúde financeira (LOSS; SARLO NETO, 2003; CIOFFI; FAMÁ, 2010; FORTI; SCHIOZER, 2015) da empresa, e que o rating também sinaliza a mesma informação (BOLDIN; LEGGETT, 1995; KHIEU; PYLES, 2016). Neste contexto, empresas com boa classificação de rating podem pagar menos dividendos, uma vez que possuem as duas formas de sinalização enquanto empresas sem rating possuem apenas os dividendos para sinalizar sua situação financeira ao mercado.

Vale ressaltar que a alegação alternativa de que empresas maiores teriam melhores condições de arcar com custos de obtenção da classificação de rating não se sustentam uma vez que o estudo controlou esta alternativa através da variável Tamanho.

As limitações deste estudo estão na possibilidade latente de relações endógenas entre as variáveis que podem resultar em viés dos estimadores, apesar dos cuidados tomados pela metodologia adotada e na amostra de empresas com classificação de rating, visto que apenas 79 empresas apresentaram esta informação. Sugere-se como estudos futuros replicar o estudo desconsiderando as empresas financeiras, que possuem características específicas, a fim de verificar se os resultados permanecem os mesmos e ampliar as variáveis de análise, conforme adotado pela literatura.

\section{Referências}

ASHRAF, Badar N.; ZHENG, Changjun Z. Shareholder protection, creditor rights and bank dividend policies. China Finance Review International, v. 5, n. 2, p. 161-186, 2015. DOI: https://doi.org/10.1108/CFRI-082014-0057

BALTAGI, Badi H. Econometric Analysis of Panel Data. 3 ed. New York: John Wiley \& Sons, 2005.

BARCLAY, Michael J.; SMITH, Clifford W. J.; WATTS, Ross L. The determinants of corporate leverage and dividend policies. Journal of Applied Corporate Finance, v. 7.4, n.1, p.4-19, 1995. DOI: 10.1111/j.17456622.1995.tb00259.x

BARROS, Lucas A. B. de C.; CASTRO JUNIOR, Francisco. H. F. de, SILVEIRA, Alexandre. D. M. da; BERGMANN, Daniel. R. A questão da endogeneidade nas pesquisas empíricas em finanças corporativas: principais problemas e formas de mitigação. In: Social Science Research Network-SSRN, 2010. DOI: http://dx.doi.org/10.2139/ssrn.1593187

BHATTACHARYA, Sudipto. Imperfect information, dividend policy, and "the bird in the hand" fallacy. The Bell Journal of Economics, v. 20, n. 1, p. 259-270, 1979. DOI: 10.2307/3003330

BLACK, Fischer. The dividend puzzle. The Journal of Portfolio Management, v. 2, p. 5-8, 1976. DOI: https://doi.org/10.3905/jpm.1976.408558

BOLDIN, Robert; LEGGETT, Keith. Bank dividend policy as a signal of bank quality. Financial Services Review, v. 4, p. 1-8, 1995. DOI: https://doi.org/10.1016/1057-0810(95)90013-6

BONE, Rosemarie. B. Ratings soberanos e corporativos: mecanismos, fundamentos e análise crítica.

Perspectiva Econômica, v. 2, n. 1, p. 46-67, 2006. Disponível em:

<http://revistas.unisinos.br/index.php/perspectiva_economica/article/view/4374>. Acesso em: 04 dez. 2018

BRASIL. Lei no 6.404, de 15 de dezembro de 1976. Dispõe sobre as Sociedades por Ações. Disponível em: <http://www.planalto.gov.br/ccivil_03/leis/L6404compilada.htm>. Acesso em: 04 dez. 2018.

BRASIL. Lei no 9.249, de 26 de dezembro de 1995. Altera a legislação do imposto de renda das pessoas jurídicas, bem como da contribuição social sobre o lucro líquido, e dá outras providências. Disponível em: <http://www.planalto.gov.br/ccivil_03/leis/l9249.htm>. Acesso em: 04 dez. 2018.

BRASIL. Lei no 9.430, de 27 de dezembro de 1996. Dispõe sobre a legislação tributária federal, as contribuições para a seguridade social, o processo administrativo de consulta e dá outras providências. Disponível em: <http://www.planalto.gov.br/ccivil_03/leis/l9430.htm>. Acesso em: 04 dez. 2018. 
BRASIL. Lei no 10.303, de 31 de outubro de 2001. Altera e acrescenta dispositivos na Lei $n^{\circ} 6.404$, de 15 de dezembro de 1976, que dispõe sobre as Sociedades por Ações, e na Lei no 6.385, de 7 de dezembro de 1976, que dispõe sobre o mercado de valores mobiliários e cria a Comissão de Valores Mobiliários.

Disponível em: <http://www.planalto.gov.br/ccivil_03/leis/leis_2001//10303.htm>. Acesso em: 04 dez. 2018.

BRASIL. Lei no 11.638, de 28 de dezembro de 2007. Altera e revoga dispositivos da Lei no 6.404, de 15 de dezembro de 1976, e da Lei no 6.385, de 7 de dezembro de 1976, e estende às sociedades de grande porte disposições relativas à elaboração e divulgação de demonstrações financeiras. Disponível em:

<http://www.planalto.gov.br/ccivil_03/_ato2007-2010/2007/lei/l11638.htm>. Acesso em: 04 dez. 2018.

BRENNAN, Michael J. Taxes, market valuation and corporate financial policy. National Tax Journal, v. 23, n. 4, p. 417-427, 1970. Disponível em: <https://www.jstor.org/stable/41792223>. Acesso em: 05 dez. 2018.

CAMERON, A. Colin; TRIVEDI, Pravin. K. Microeconometrics: methods and applications.

Cambridge: Cambridge University Press, 2005.

CHANG, Bin; DUTTA, Shantanu; SAADI, Samir; ZHU, Pengcheng. Corporate governance and dividend payout policy: beyond country-level governance. Journal of Financial Research, v. 41, n. 4, p. 445-484, 2018. DOI: http://dx.doi.org/10.2139/ssrn.2994960

CIOFFI, Patrícia. L. de M.; FAMÁ, Rubens. O modelo de Ohlson e a sinalização de dividendos no mercado de capitais brasileiro. In: SEMINÁRIOS EM ADMINISTRAÇÃO -SEMEAD, 13., 2010, São Paulo. Anais ... São Paulo: SEMEAD, 2010. Disponível em:

<http://sistema.semead.com.br/13semead/resultado/trabalhosPDF/65.pdf>. Acesso em: 04 dez. 2018.

CORREIA, Laise F.; AMARAL, Hudson. F. O impacto da política de dividendos sobre a rentabilidade de títulos negociados na Bovespa no período de 1994 a 2000. In: ENCONTRO NACIONAL ANPAD, 26., 2002, Salvador. Anais... Salvador: ANPAD, 2002. Disponível em:

<http://www.anpad.org.br/admin/pdf/enanpad2002-fin-195.pdf>. Acesso em: 04 dez. 2018.

DAMASCENO, Danilo. L.; ARTES, Rinaldo; MINARDI, Andrea. M. A. F. Determinação de rating de crédito de empresas brasileiras com a utilização de índices contábeis. Revista de Administração - USP, São Paulo, v. 43, n. 4, p. 344-355, out./nov./dez. 2008. Disponível em:

$<$ http://www.spell.org.br/documentos/ver/4421/determinacao-de-rating-de-credito-de-empresas-brasileirascom-a-utilizacao-de-indices-contabeis/i/pt-br>. Acesso em: 05 dez. 2018.

DICKENS, Ross. N.; CASEY, K. Michael; NEWMAN, Joseph A. Bank dividend policy: explanatory factors. Quarterly Journal of Business and Economics, v. 41, n. 1/2, p. 3-12, 2002. Disponível em: $<$ https://www.jstor.org/stable/40473341>. Acesso em: 05 dez. 2018.

FAMA, Eugene; FRENCH, Kenneth. Disappearing dividends: changing firm characteristics or lower propensity to pay? Journal of Financial Economics, v. 60, n. 1, p. 3-44, 2001. DOI: 10.1016/S0304$405 \times(01) 00038-1$

FIGUEIREDO, Antônio C. O conteúdo informativo de dividendos: evidências no Brasil. In: ENCONTRO BRASILEIRO DE FINANÇAS, 2., 22 e 23 jul. 2002, Rio de Janeiro. Anais... Rio de Janeiro: IBMEC, 2002. Disponível em: <http://bibliotecadigital.fgv.br/ocs/index.php/ebf/2EBF/paper/viewFile/1655/766>. Acesso em: 05 dez. 2018.

FIORATI, Alexandre. R. dos S; GARCIA, Fabio G; TAMBOSI FILHO, Elmo. Dividendos e juros sobre capital próprio: sinalização de lucratividade futura? Estudo no mercado brasileiro 1999/2004. In: ENCONTRO DA ANPAD, 31, 22 a 26 set. 2007, Rio de Janeiro. Anais... Rio de Janeiro: ENANPAD, 2007. Disponível em: <http://www.anpad.org.br/admin/pdf/FIN-B580.pdf>. Acesso em: 05 dez. 2018.

FORTI, Cristiano A. B.; SCHIOZER, Rafael F. Bank dividends and signaling to information-sensitive depositors. Journal of Banking \& Finance, v. 56, p. 1-11, 2015. DOI:

https://doi.org/10.1016/j.jbankfin.2015.02.011

FORTI, Cristiano A. B.; PEIXOTO, Fernanda M.; ALVES, Denis L. Determinant factors of dividend payments in Brazil. Revista Contabilidade e Finanças - USP, São Paulo, v. 26, n. 68, p. 167-180, 2015. DOI: http://dx.doi.org/10.1590/1808-057x201512260 
FUTEMA, Mariano S.; BASSO, Leonardo F. C.; KAYO, Eduardo K. Estrutura de capital, dividendos e juros sobre o capital próprio: testes no Brasil. Revista Contabilidade e Finanças- USP, São Paulo, v. 20, n. 49, p. 44-62, jan./abr. 2009. DOI: https://doi.org/10.1590/S1519-70772009000100004

GALVÃO, Kécia da S.; SANTOS, Joséte F. dos; ARAÚJO, Jevuks M. Dividendos, juros sobre capital próprio e níveis de payout: um estudo investigativo sobre a política de distribuição de dividendos adotada pelas empresas listadas na BM\&FBovespa. Revista Contemporânea de Contabilidade, Florianópolis, v. 15, n. 36, p. 3-30, dez. 2018. DOI: https://doi.org/10.5007/2175-8069.2018v15n36p3.

GALVÃO, Kécia da S.; SANTOS, Joséte F. dos; ARAÚJO, Jevuks M. Política de distribuição de dividendos: uma análise dos fatores relacionados ao pagamento de dividendos e do payout incremental pelas empresas brasileiras. Enfoque: Reflexão Contábil, v. 38, n. 3, p. 57-75, 2019. DOI:

https://doi.org/10.4025/enfoque.v38i3.42438

GORDON, Myron J. Dividends, earnings, and stock prices. The Review of Economics and Statistics, v. 41, n. 2, p. 99-105, 1959. DOI: 10.2307/1927792.

HEINEBERG, Ricardo; PROCIANOY, Jairo L. Aspectos determinantes do pagamento de proventos em dinheiro das empresas com ações negociadas na Bovespa. In: ENCONTRO DA ANPAD, 27, 2003, Atibaia. Anais... Atibaia: ANPAD, 2003. Disponível em: <http://www.anpad.org.br/admin/pdf/enanpad2003-fin1222.pdf>. Acesso em: 02 mai. 2020.

JENSEN, Michael C.; MECKLING, William H. Theory of the firm: managerial behavior, agency costs and ownership structure. Journal of Financial Economics, v. 3, n. 4, p. 305-360, 1976. DOI:

https://doi.org/10.1016/0304-405X(76)90026-X

KHIEU, Hinh D.; PYLES, Mark K. The influence of a credit rating change on dividend and investment policy interactions. The Financial Review, v. 51, n. 4, p. 579-611, 2016. DOI: https://doi.org/10.1111/fire.12104

LINTNER, John. Distribution of incomes of corporations among dividends, retained earnings, and taxes. The American Economic Review, v. 46, n. 2, p. 97-113, 1956. Disponível em:

<https://www.jstor.org/stable/1910664>. Acesso em: 05 dez. 2018.

LITZENBERGER, Robert H.; RAMASWAMY, Krishna. The effect of personal taxes and dividends on capital asset prices: theory and empirical evidence. Journal of Financial Economics, v. 7, n. 2, p. 163-195, 1979. DOI: https://doi.org/10.1016/0304-405X(79)90012-6

LOSS, Lenita; SARLO NETO, Alfredo. O inter-relacionamento entre políticas de dividendos e de investimentos: estudo aplicado às companhias brasileiras negociadas na Bovespa. Revista Contabilidade e Finanças - USP, São Paulo, v. 17, n. 40, p. 52-66, jan./abr. 2006. DOI: http://dx.doi.org/10.1590/S151970772006000100005

LOSS, Lenita; SARLO NETO, Alfredo. Política de dividendos, na prática, é importante? Revista Contabilidade e Finanças - USP, São Paulo, v.14, n. especial, p. 39-53, out. 2003. DOI: http://dx.doi.org/10.1590/S1519-70772003000400008

MALAQUIAS, Rodrigo F.; GIACHERO, Osvaldo S.; COSTA, Brener E. da; LEMES, Sirlei. Juros sobre o capital próprio: uma análise envolvendo a empresa pagadora e o acionista recebedor. UNB Contábil UNB, Brasília, v.10, n. 2, jul./dez, 2007. Disponível em:

<https://www.revistacgg.org/contabil/article/view/245/0>. Acesso em: 05 dez. 2018.

MARTINS, Andressa I.; FAMÁ, Rubens. O que revelam os estudos realizados no Brasil sobre política de dividendos? Revista de Administração de Empresas, São Paulo, v. 52, n. 1, p. 24-39, jan./fev. 2012. DOI: http://dx.doi.org/10.1590/S0034-75902012000100003

MARTINS, Theo C.; NOVAES, Walter. Mandatory dividend rules: do they make it harder for firms to invest? Journal of Corporate Finance, v. 18, n. 4), p. 953-967, 2012. DOI:

https://doi.org/10.1016/j.jcorpfin.2012.05.002

MATSUMOTO, Alberto S.; FERNANDES, José L. B.; BOURAHLI, Abdelkader; CARDOSO, João Paulo. O rating tem o poder preditivo de insolvência? In: SEMINÁRIOS EM ADMINISTRAÇÃO-SEMEAD, 14, 2011, São Paulo. Anais ... São Paulo: SEMEAD, 2011. Disponível em:

<http://sistema.semead.com.br/14semead/resultado/trabalhosPDF/274.pdf>. Acesso em: 10 jan. 2019. 
MILLER, Merton H.; MODIGLIANI, Franco. Dividend policy, growth and the valuation of shares. The Journal of Business, v. 34, n. 4, p. 411-433, 1961. Disponível em: <http://www.jstor.org/stable/2351143>. Acesso em: 05 dez. 2018.

NEVES JUNIOR, José das; MATSUMOTO, Alberto S.; ARAUJO, Silvia S. R. Grau de investimento: uma análise comparativa do desempenho Brasil em relação à Argentina, Chile, México, Uruguai e Venezuela, na visão do rating da Moody's Group. In: CONGRESSO INTERNACIONAL DE COSTOS, 10, 13, 14 e 15 de junho de 2007, Lyon/França. Anais... Lyon/França: Instituto Internacional de Custos, 2007. Disponível em: <http://intercostos.org/documentos/apellidos/Das\%20Neves\%202.pdf>. Acesso em: 05 dez. 2018

NISSIM, Doron; ZIV, Amir. Dividend changes and future profitability. The Journal of Finance, Cambridge, v. 56, n. 6; p. 2111-2133, Dec./2001. DOI: https://doi.org/10.1111/0022-1082.00400

NOVIS NETO, Jorge A. SAITO, Richard. Pagamentos de dividendos e persistência de retornos anormais das ações: evidência do mercado brasileiro. Revista de Administração, São Paulo, v. 38, n. 2, p. 135-143, abr./jun. 2003. Disponível em: <http://www.spell.org.br/documentos/ver/16724/pagamentos-de-dividendos-epersistencia-de-retornos-anormais-das-acoes--evidencia-do-mercado-brasileiro/i/pt-br>. Acesso em: 04 dez. 2018.

PARTNOY, Frank. The Paradox of Credit Ratings. U San Diego Law \& Econ Research Paper, n. 20, 2001. DOI: http://dx.doi.org/10.2139/ssrn.285162

RAMASASTRY, Ambarish; KOSE, John; WILLIAMS, Joseph. Efficient signalling with dividends and investments. The Journal of Finance, v. 42, n. 2, p. 321-343, 1987. DOI: 10.2307/2328255

REDDY, Y. V. Credit rating: changing perspectives, 2000. Disponível em: <http://rbidocs.rbi.org.in/rdocs/Bulletin/PDFs/13292.pdf.>. Acesso: 04 dez. 2018.

ROODMAN, David. How to do xtabond2: an introduction to difference and system GMM in Stata. Stata Journal, v. 9,, p. 86-136, 2009. DOI: https://doi.org/10.1177/1536867X0900900106

ROSENBAUM, Paul R.; RUBIN, Donald B. The central role of the propensity score in observational studies or casual effects. Biometrika, v. 70, p. 41-55, 1983. DOI: 10.1093/biomet/70.1.41

SANTOS, José L. dos; SCHMIDT, Paulo. Contabilidade Societária. 4.ed. São Paulo: Atlas, 2011.

SHAO, Liang; KWOK, Chuck C. Y.; GUEDHAMI, Omrane. Dividend policy: balancing shareholders' and creditors' interests. Journal of Financial Research, v. 36, n. 1, p. 43-66, 2013. DOI:

https://doi.org/10.1111/j.1475-6803.2013.12002.x

SILVEIRA, Rafaela A. C.; TAKAMATSU, Renata T.; AVELINO, Bruna C. Impacto dos ratings de crédito nas ações de empresas de capital aberto no Brasil. RACE - Revista de Administração, Contabilidade e Economia, v. 16, n. 2, p. 573-602, 2017. DOI: http://dx.doi.org/10.18593/race.v16i2.10556

VANCIN, Daniel F.; PROCIANOY, Jairo L. Os determinantes do pagamento de dividendos: o efeito do mínimo obrigatório legal e contratual nas empresas brasileiras. Revista Brasileira de Finanças, v. 14, n. 1, p. 89-123, abr. 2016. ISSN 1984-5146. DOI: http://dx.doi.org/10.12660/rbfin.v14n1.2016.53448

WOOLDRIGDE, Jeffrey. M. Econometric analysis of cross section and panel data. Cambrigde, MA: MIT Press, 2002.

$\mathrm{XIA}$, Han. Can investor-paid credit rating agencies improve the information quality of issuer-paid rating agencies? Journal of Financial Economics, v. 111, n. 2, p. 450-468, 2014. DOI:

https://doi.org/10.1016/j.jfineco.2013.10.015

\section{NOTAS}

\section{AGRADECIMENTOS}

Não se aplica.

\section{CONTRIBUIÇÃO DE AUTORIA}

Concepção e elaboração do manuscrito: K. S. Freitas e C.A.B. Forti

Coleta de dados: K. S. Freitas 
Análise de dados: C.A.B. Forti

Discussão dos resultados: C.A.B. Forti e K. S. Freitas

Revisão e aprovação: C.A.B. Forti e K. S. Freitas

\title{
CONJUNTO DE DADOS DE PESQUISA
}

O conjunto de dados que dá suporte aos resultados deste estudo não está disponível publicamente.

\section{FINANCIAMENTO}

Não se aplica.

\section{CONSENTIMENTO DE USO DE IMAGEM}

Não se aplica.

\author{
APROVAÇÃO DE COMITÊ DE ÉTICA EM PESQUISA \\ Não se aplica.
}

\section{CONFLITO DE INTERESSES}

Não se aplica.

\section{LICENÇA DE USO}

Os Direitos Autorais para artigos publicados neste periódico são do autor, com direitos de primeira publicação para a Revista. Em virtude de aparecerem nesta Revista de acesso público, os artigos são de uso gratuito, com atribuições próprias, em aplicações educacionais, de exercício profissional e para gestão pública. A Revista adotou a licença Creative Commons Atribuição 4.0 Internacional - CC BY NC ND. Esta licença permite acessar, baixar (download), copiar, imprimir, compartilhar, reutilizar e distribuir os artigos desde que com a citação da fonte, atribuindo os devidos créditos de autoria. Nesses casos, nenhuma permissão é necessária por parte dos autores ou dos editores. Autores têm autorização para assumir contratos adicionais separadamente, para distribuição não-exclusiva da versão do trabalho publicada nesta revista (ex.: publicar em repositório institucional ou um capítulo de livro).

\section{PUBLISHER}

Universidade Federal de Santa Catarina. Curso de Ciências Contábeis e Programa de Pós-graduação em Contabilidade. Publicação no Portal de Periódicos UFSC. As ideias expressadas neste artigo são de responsabilidade de seus autores, não representando, necessariamente, a opinião dos editores ou da universidade.

\section{EDITORES}

Carlos Eduardo Facin Lavarda e Suliani Rover

\section{HISTÓRICO}

Recebido em: 26/05/2019 - Revisado por pares em: 02/10/2019 - Reformulado em: 15/05/2020 Recomendado para publicação em: 17/05/2020 - Publicado em: 30/05/2020

Uma versão preprint do artigo foi apresentada no XIV Encontro Brasileiro de Finanças, 2014. 